UNIVERSIDADE FEDERAL DO RIO GRANDE DO SUL

Centro Interdisciplinar de Novas Tecnologias na Educação

IV Ciclo de Palestras:

Inovações em Tecnologia na Educação: Processos e Produtos

Relato de Experiência

SOFTWARE LIVRE: PERSPECTIVAS TEÓRICAS E PRÁTICAS DE UTILIZAÇÃO NA INFORMÁTICA EDUCACIONAL

Porto Alegre, Setembro de 2004 


\title{
Software livre: perspectivas teóricas e práticas de utilização na informática educacional
}

\author{
Jossiane Boyen Bitencourt* \\ Marlise Bock Santos**
}

\section{Resumo}

Palavras-chave: informática na educação, software livre, linux e informática

Este trabalho relata a experiência de mudança de software proprietário para software livre no Colégio Batista (POA), instituição privada de educação básica. A superação de alguns desafios impostos por limitações econômicas e técnicas levou a Escola a buscar uma solução alternativa à constante necessidade de renovação de hardware e licenças de softwares. Além disto, a filosofia do software livre e sua possibilidade de democratização do conhecimento veio ao encontro do projeto políticopedagógico elaborado pela comunidade escolar. A implementação da plataforma Linux possibilitou a adequação do sistema às necessidades locais, ou seja: superar um atrelamento financeiro e técnico ao sistema Windows, seus aplicativos e softwares educacionais de paradigmas fechados. Novos caminhos foram abertos a partir das mudanças realizadas, como a rápida aquisição dos conhecimentos pela equipe técnica e pedagógica, para dar suporte às ações propostas pela Escola. Salienta-se também uma maior autonomia e a busca de novos saberes, visto que a acessibilidade do software livre está relacionada à pesquisa constante de novas soluções para as necessidade que surgem. Atualmente, um ano depois, soluções diferenciadas têm sido dadas fora do paradigma do software proprietário. As atividades propostas demonstram a ampla utilização pedagógica criativa e autônoma de uma proposta alternativa ao sistema hegemônico.

\footnotetext{
* Graduada em Pedagogia Multimeios e Informática Educativa pela PUCRS

Aluna Especial no Mestrado em Educação pela UFRGS

Instituição: Colégio Batista

Função: Professora de informática aplicada à educação

E-mail: jossi@colegiobatista.org.br

Home-page: www.colegiobatista.org.br/ jossi/pessoal

* Graduada em Pedagogia - Séries Iniciais pela UFRGS

Mestre em Educação pela PUCRS

Aluna Especial no Doutorado em Educação pela UFRGS

Instituição: Colégio Batista

Função: Coordenadora Pedagógica

E-mail: marlisesantos@ colegiobatista.org.br
} 
$-\int$ CINTED-UFRGS Novas Tecnologias na Educaçãa

\title{
Theoretical and practical perspectives of use of free software in educational computing
}

\author{
Abstract \\ Word-key: computing and education, free software, Linux and computing
}

This paper tells to the experience of software change proprietor for free software in "Colégio Batista" (Porto Alegre), a private institution of basic education. The overcoming of some challenges, due to economic limitation and technical matters, took the School to search an alternative solution to the constant necessity of renewal of the hardware and licenses of softwares. Beyond this, the philosophy of free software and its possibility of democratization of knowledge came to the meeting of the politicianpedagogical project elaborated by the school community. The implementation of the Linux platform made possible adequacy of the system to the local necessities, or either: to surpass a financial and technical bond to the Windows system and its packages of educational softwares of closed paradigms. New ways had been opened from the carried through changes, as the fast acquisition of the knowledge for the pedagogical and technical team, to give support to the actions proposals by the School. We point ou also a bigger autonomy and the search of new knowledges, since the accessibility of free software is related to the constant research of new solutions for the necessities that may appear. Currently, one year later, differentiated solutions have been given outside of the paradigm of software proprietor. The activities proposals demonstrate the ample use of pedagogical creative and independent of a proposal alternative to the hegemonic system. 
O presente trabalho visa mostrar a utilidade do software livre na Instituição abordando diversos setores, mas principalmente no setor de Informática da Educação. Pretende-se relatar a experiência de migração do software proprietário para uma plataforma livre mostrando sua utilização pedagógica com alunos e professores.

A superação de alguns desafios impostos por limitações econômicas e técnicas levou a Escola a buscar uma solução alternativa à constante necessidade de renovação de hardware e licenças de softwares. Esta situação impossibilitava a utilização de novas tecnologias, visto serem de alto custo e pouco tempo útil. Os desafios vieram do pouco conhecimento sobre o assunto, o que é justamente resultado do forte monopólio da plataforma proprietária nas instituições de ensino. $\mathrm{O}$ condicionamento dos alunos e professores a uma interface conhecida também pode ser apontado como um desafio ainda a ser superado.

Esta situação impossibilitava a utilização de novas tecnologias com objetivos pedagógicos. Dentre as dificuldades enfrentadas estava a utilização de equipamentos obsoletos onde os programas e softwares educacionais apresentavam dificuldades de performance. Além disto, o acesso à Internet era praticamente inviável devido ao fato de que a rede estava muito lenta e o próprio navegador Web não suportava muitos sites por pela impossibilidade de novas atualizações.

Estes equipamentos com configuração de $100 \mathrm{Mz}$ com 16 a 32 Mb de memória RAM utilizados com uma plataforma proprietária, nos dias de hoje, ficariam inoperantes e necessitariam ser desatualizados. A alternativa viável foi a aquisição de apenas um servidor potente e a utilização das máquinas antigas como terminais remotos, utilizando o Sistema Operacional Linux e seus aplicativos como ferramentas pedagógicas importantes no processo de ensino-aprendizagem de alunos e professores que não conheciam os recursos.

No início o pouco conhecimento técnico foi um dos principais problemas na implantação do novo sistema diante da dificuldade da instalação e configuração dos terminais, ocorrendo problemas freqüentes na rede e em alguns programas. Hoje, depois de muitos testes, de descobertas advindas de pesquisa e curiosidade da área técnica, o sistema opera com tranqüilidade e boa confiabilidade, possibilitando o acesso à Internet além da utilização dos aplicativos e programas mais utilizados no Linux por alunos, professores e funcionários.

A filosofia do software livre e sua possibilidade de democratização do conhecimento e inclusão digital veio ao encontro do projeto político-pedagógico elaborado pela comunidade escolar. A implementação da plataforma Linux possibilitou a adequação do sistema às necessidades locais, ou seja: superar um atrelamento financeiro e técnico ao sistema Windows, seus aplicativos e softwares educacionais de paradigmas fechados, trabalhando com o processo de construção de atividades pelos próprios alunos que utilizam a ferramenta como co-autores de seu processo aprendizagem, pesquisando, resolvendo problemas e construindo suas próprias hipóteses.

Segundo Valente ( 1998 ), “ O computador deve propiciar condições para os estudantes exercitarem a capacidade de procurar e selecionar informações, resolver problemas $e$ aprender independente." ( Pg. 06 )

Novos caminhos foram abertos a partir das mudanças realizadas, como a rápida aquisição dos conhecimentos pela equipe técnica e pedagógica, para dar suporte às ações propostas pela Escola. Salienta-se também uma maior autonomia e a busca de 
novos saberes, visto que a acessibilidade do software livre está relacionada à pesquisa constante de novas soluções para as necessidade que surgem principalmente em relação a softwares educacionais de paradigma aberto e aplicações diretamente na Web em constante expansão.

Outra questão importante desta preparação da equipe pedagógica, incluindo os professores, é a utilização dos programas com seus alunos na informática e não somente conhecê-los para benefício próprio. Nas capacitações a ênfase é dada ao conhecimento da ferramenta mas principalmente sua utilização pedagógica em sala de aula.

- $\quad$ Segundo Freire \& Prado ( 1996 ) apud Valente ( 1999 ), “ A formação dos professores deve propiciar as condições para o mesmo agir, refletir e depurar o seu conhecimento em todas as fases pelas quais ele deverá passar na implantação do computador e na sua prática pedagógica em sala de aula: dominar o computador e saber interagir com o aluno, com a classe como um todo e desenvolver projetos integrados com a ferramenta." ( Pg. 14 )

O professor deve ser um facilitador da aprendizagem deste aluno que tem grande domínio destas tecnologias. O computador e a internet fazem parte da vida de crianças e adolescentes e nada mais justo que aproveitá-las em sala de aula, relacionando os conhecimentos com atividades de pesquisa e construção de novos saberes. A interação entre ambos pode ser facilitada quando utilizam ferramentas que motivam o aluno a aprender a aprender.

Soluções diferenciadas têm sido dadas fora do paradigma do software proprietário. As atividades desenvolvidas, demonstram a ampla utilização pedagógica criativa e autônoma de uma proposta alternativa ao sistema hegemônico. Uma delas é utilizar os editores de texto e de apresentação do OpenOffice para realização de atividades como: produções textuais, livros digitais, dicionários, criação de logotipos, gifs animados, histórias em quadrinhos entre outras opções que podem ser tranquiilamente exploradas. Essas ferramentas podem ser utilizadas em qualquer disciplina com qualquer e interdisciplinarmente onde o conhecimento é interliga e fica ainda mais significativo ao aluno.

Para realização destas atividades podem ser usados editores de desenho e a própria busca de imagens da Internet para implementar o trabalho realizado nestas ferramentas, geralmente destinadas a serem utilizadas meramente como suíte de escritório. Estas ferramentas estão sendo muito utilizadas desde a Educação Infantil ao Ensino Médio.

Segundo Valente ( 1998 ), “....um processador de texto, permite representar idéias sendo o computador uma ferramenta que permite ao aprendiz resolver problemas como desenhar, escrever, comunicar-se, etc..." ( pg.03)

Outras ferramentas livres, de ensino cooperativo e colaborativo, que podem ser aproveitadas são as ferramentas de educação a distância como TelEduc, Wiki (ferramenta para escrita colaborativa na Web ) e os Blogs (diários virtuais). Todas elas são baseadas em software livre e utilizadas na instituição.

O TelEduc é um ambiente de Educação a Distância baseado em software livre desenvolvido pela UNICAMP que disponibiliza ferramentas síncronas e assíncronas como fóruns de discussão, chat, diários de bordo proporcionando aos usuários a troca de 
saberes sem estar presencialmente em sala de aula. O Wiki é uma ferramenta livre que propicia a escrita de textos cooperativamente, porém não ao mesmo tempo. Quando um usuário está usando determinada página, o outro deve esperar ele se desconectar. $\mathrm{O}$ interessante nesta ferramenta é que todos podem mexer no texto do outro realizando uma aprendizagem cíclica que não tem fim.

No momento estão sendo desenvolvidos vários projetos com essas ferramentas. Dois projetos paralelos no ambiente TelEduc: um de capacitação de professores para utilização da ferramenta entre os mesmos e com os alunos. Outro com uma turma do $2^{\mathrm{a}}$ ano do Ensino Médio destinado à criação e realização de questões de Matemática visando à interação, através do levantamento e discussão de dúvidas entre os alunos e o professor, solucionando problemas em equipe.

Já com o Wiki, está sendo realizado um projeto com um grupo de alunos monitores discutindo questões sobre o software livre como definições, importância na sociedade, vantagens e desvantagens entre outras questões pertinentes. Por último, com uma turma de $1^{\circ}$ ano está sendo construído um blog, que é uma página Web em formato de notícias em ordem cronológica, onde está acontecendo uma discussão sobre o uso de drogas na adolescência.

Os caminhos a percorrer ainda são tantos quantos nosso olhar estiver disposto a captar. A inserção de alunos, professores e monitores em realidades mediadas por uma interface computacional é um campo aberto para questionamentos e análises críticas de uma realidade que está se constituindo na Educação como um novo campo de saber. 


\section{Considerações Finais}

As recentes propostas na área da Educação que vêm se configurando a partir da utilização de Tecnologias da Informação e da Comunicação (TICs), fazem emergir também a necessidade de singrar nas ondas destas novas possibilidades. Não pelo modismo ou euforia que as tecnologias produzem em muitas instâncias do social, mas para que seja possível a crítica constante que dimensiona o papel da tecnologia e sua aplicação à Educação.

É recorrente no cotidiano o discurso eufórico dos avanços tecnológicos que vêm ocorrendo nas últimas décadas e que produzem mudanças profundas em diversos aspectos do tecido social. As chamadas novas tecnologias da informação e da comunicação, já não tão novas assim, são aclamadas como revolucionárias e transformadoras.

Deleuze (1992) fala das diferentes sociedades fazendo uma distinção entre as máquinas correspondentes a cada tipo de sociedade. As antigas sociedades de soberania lidavam com máquinas simples, roldanas, alavancas. As sociedades disciplinares, que são mais recentes e que apesar de viverem em crise, ainda se encontram presentes coabitando com um novo tipo de sociedade que está emergindo, tinham como máquinas equipamentos energéticos, a fábrica.

$\mathrm{Na}$ contemporaneidade, as sociedades de controle operam por máquinas de informática e computadores. Para este autor não se trata de uma evolução tecnológica, mas de uma mutação do capitalismo, que vai do capitalismo do século XIX de características produtivas, de propriedade e que tem na fábrica seu meio de confinamento, para o capitalismo voltado para o produto, para a venda, para o mercado.

As mutações técnico-científicas estão inseridas dentro de um contexto do modo de produção capitalista. Tschiedel (1998, p: 41) afirma que na sociedade capitalista são intensos os processos de individuação que estão relacionados à massificação, ao empobrecimento no qual os sujeitos estão colocados à margem do mercado-consumo. Em contrapartida, o processo de singularização ${ }^{1}$ opera rupturas, surpresas que se colocam à margem da massificação, ele não é classificável. Ele é acima de tudo inédito e passa, para cada um, pela vivência e apropriação dos fenômenos. "A singularização conduz à afirmação de potência, à desnaturalização dos fatos e à criação de outros modos de existência. Isto significa abrir mão de modelos pré-estabelecidos, planos homogêneos, unificações".

A evolução tecnológica aliada à Educação pode ser um caminho de resingularização da própria Educação, fazendo emergir elementos como o acesso a informações de todo tipo e o alto grau de interatividade entre os participantes, entre outros. Rajchman (2000, p:405) diz que "as tecnologias estão longe de serem simples próteses, contribuindo, antes, para determinar os campos do possível nos quais nos tornamos o que somos".

É operando rupturas e desenhando linhas de fuga que o software livre tem sua condição de opor resistência às plataformas proprietárias que homogeneízam e engessam as possibilidades de movimento e criação.

No caso da instituição em questão, foi o caminho aberto pelo software livre que deu o fôlego necessário para que as propostas de informática educativa pudessem avançar e dar novos sentidos para o trabalho realizado. A adequação da alternativa encontrada às necessidades da Escola tem aberto novos horizontes naquilo que se pode

\footnotetext{
${ }^{1}$ Processo de singularização tem o sentido dado por Guattari e Rolnik (1999, p 47) de "[...] algo que pode conduzir à afirmação de valores num registro particular, independentemente das escalas de valor que nos cercam e espreitam de todos os lados". 
fazer sem o atrelamento econômico e intelectual a softwares que aprisionam, com seus códigos fechados e suas licenças que a cada novo ciclo obrigam seus usuários a investir quantias exorbitantes para a utilização legal do produto.

O software livre é então uma alternativa viável para qualquer instituição educacional empenhada em democratizar o acesso às ferramentas disponíveis para a utilização no seu processo pedagógico. As realizações que vão surgindo nesta trajetória e o uso criativo das ferramentas são a prova de que é preciso impor uma resistência à prepotência econômica de grandes grupos dominantes. 


\section{Referências Bibliográficas}

DELEUZE, Gilles. Conversações. São Paulo: Editora 34, 1992.

GUATTARI, Félix, ROLNIK, Suely. Micropolítica: Cartografias do Desejo. Petrópolis: Vozes, 1999.

RAJCHMAN, John . Existe uma inteligência do virtual? In: ALLIEZ, Éric (org.). Gilles Deleuze: Uma vida filosófica. São Paulo: Editora 34, 2000.

TSCHIEDEL, Rosemarie Gärtner. O grupo como espaço de construção: da heterogeneidade à heterogênese. Porto Alegre: PUCRS, 1998. Dissertação (Mestrado em Psicologia Social e da Personalidade), Faculdade de Psicologia, PUCRS, 1998.

VALENTE, José Armando (org). Computadores e Conhecimento: Repensando a Educação, $2^{a}$ edição, Campinas, São Paulo: UNICAMP/NIED, 1998.

Paulo: UNICAMP/NIED, 1999.

(org). O computador na sociedade do conhecimento. São 